\title{
Chalconoid Derived Heterocycles as Potent Bioactive Molecules: A Review
}

\section{Sapra $\mathbf{S}^{1 *}$, Sharma $\mathbf{K}^{1}$, Bhalla $\mathbf{Y}^{2}$ and Dhar $\mathrm{KL}^{1}$}

${ }^{1}$ School of Pharmaceutical Sciences, Shoolini University, Solan, Himachal Pradesh, India

${ }^{2}$ Department of Pharmaceutical Chemistry, University Institute of Pharmaceutical Sciences, Panjab University, Chandigarh, India

\begin{abstract}
Although chalcones symbolize an important pharmacophore for variety of biological actions, however their analogues are also reported to be equally important for plethora of biological actions. In the present review, a comprehensive study of chalcones derived molecules (like pyrazoles, isoxazoles, pyridine, pyrimidine) their pharmacological actions, mechanism of action, structure activity relationship studies have been described.
\end{abstract}

Keywords: Chalcones; Pyrazoles; Pyridine; Pyrimidine; Anticancer; Antimicrobial

\section{Introduction}

Chalcones are considered as precursor of flavones in the biosynthesis of flavonoids. These are aromatic ketones bearing 1,3-diaryl-2-propen1 -one framework and appears to be an open chain flavonoids in which two aromatic rings are joined by three carbons with $\alpha-\beta$ unsaturated system. Chalcones are widely spread in nature (fruits, vegetables, spices, tea and soy based food stuff) and their 2'-hydroxy derivatives play an important role in the flavonoid synthesis and biosynthesis as both precursors and products [1]. They contain ketoethylinic group $(-\mathrm{CO}-\mathrm{CH}=\mathrm{CH})$ and exist in cis and trans form due to the presence of double bond in which trans form is thermodynamically more stable [2]. The conjugated double bond produces the delocalization of $\pi$ electrons which reduces its electrophilic character and makes it an intermediate for the synthesis of various biologically important heterocycles such as pyrazoline, oxazoline, thiazine, oxazine, pyrimidine etc. Thus synthesis of chalcones has generated vast interest to organic as well as medicinal chemists [3]. Formation of these nuclei involves cyclization of $\alpha-\beta$ unsaturated system of chalcones. Chalcones and its analogues have numerous pharmacological activities such as antimicrobial $[4,5]$, antiinflammatory analgesic, antiviral, antioxidant, anticancer, antimalarial, antiprotozoal, anticonvulsant [6-15] (Figure 1).

\section{Chemistry}

In general chalcones are synthesized by Claisen-Schmidt condensation of aldehyde and ketone by base catalyzed or acid catalyzed followed by dehydration to yield chalcones [16]

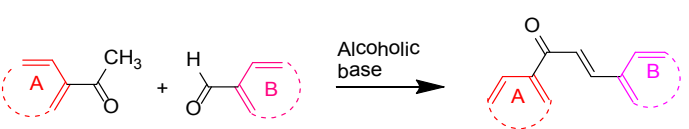

Chalcones basically consist of three plane moieties, carbon-carbon double bond and two benzene rings. The dihedral angle from the plane of $\mathrm{C} 7 / \mathrm{C} 8 / \mathrm{C} 9$ to the phenyl ring $\mathrm{A}$ is $13.8(1)^{\circ}$ and ring $\mathrm{B}$ is $2.6(1)^{\circ}$. This shows that the $\mathrm{C} 7-\mathrm{C} 8-\mathrm{C} 9$ fragment lies in the phenyl ring plane [17].<smiles>O=C(C=Cc1ccccc1)c1ccccc1</smiles>

In Figure 2, Xanthohumol (XN), prenylated chalcone from hops (Humulus lupulus L.) exhibits a wealth of pharmacological actions which includes anti-proliferative, anti-inflammatory, antioxidant, proapoptotic, anti-bacterial and anti-adhesive effects [18].

\section{Analogues of chalcones}

Pyrazoline analogues with various pharmacological activities: Pyrazole nucleus present in compounds exhibit wide range of biological activity. Introduction of a pyrazole ring in the chalcones between the two aryl rings increase the cytotoxic activity against a series of human cancer cell lines. Dhar et al. [19] synthesized a series of 1-acetyl-3,5diaryl-4,5-dihydro-(H)- pyrazoles and assayed for in vitro cytotoxicity against PC-3, OVCAR, IMR-32, HEP-2 human cancer cell lines, compound 1 showed broad spectrum cytotoxic activity against all the four cell lines. The activity shown by the compounds conclude that (i) Substitution on phenyl ring showed marked effect on cytotoxic activity, (ii) Presence of electron donating groups on phenyl ring led to enhanced activity whereas electron withdrawing group except $\mathrm{NO}_{2}$ reduces the cytotoxic activity, (iii) Replacement of phenyl ring with heterocyclic ring also reduces the cytotoxic potential and napthyl ring on both sides are more beneficial for cytotoxic potential ${ }^{15}$. Pyrazolines of methoxy substituted chalconoids of 2-acetyl napthlene were synthesized and its cytotoxic potential was analyzed against HeLa, HCT 15, A549 cancer cell lines. 3,4,5 trimethoxy substituted have shown good activity against these cell lines having $\mathrm{IC}_{50}$ value in the range of $0.037-0.019 \mu \mathrm{M}(2)$ [20]. Furopyrazole compound 3 induces terminal differentiation of HL-60 cells toward granulocyte lineage and promoted HL-60 cell differentiation by regulation of Bcl-2 and c-Myc proteins [21]. Dhar

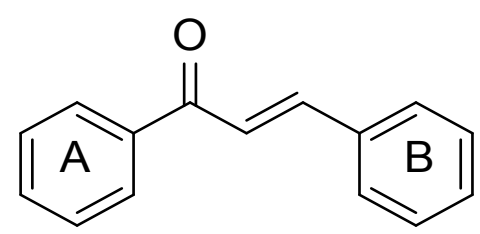

Figure 1: General structure of chalcone.

*Corresponding author: Sameer Sapra, School of Pharmaceutical Sciences, Shoolini University, Solan, Himachal Pradesh, India, Tel: +911792654048; Fax +1792308000; E-mail: sameersapra@shooliniuniversity.com

Received May 05, 2016; Accepted May 18, 2016; Published May 25, 2016

Citation: Sapra S, Sharma K, Bhalla Y, Dhar KL (2016) Chalconoid Derived Heterocycles as Potent Bioactive Molecules: A Review. Chem Sci J 7: 129. doi:10.4172/2150-3494.1000129

Copyright: @ 2016 Sapra S, et al. This is an open-access article distributed under the terms of the Creative Commons Attribution License, which permits unrestricted use, distribution, and reproduction in any medium, provided the original author and source are credited. 


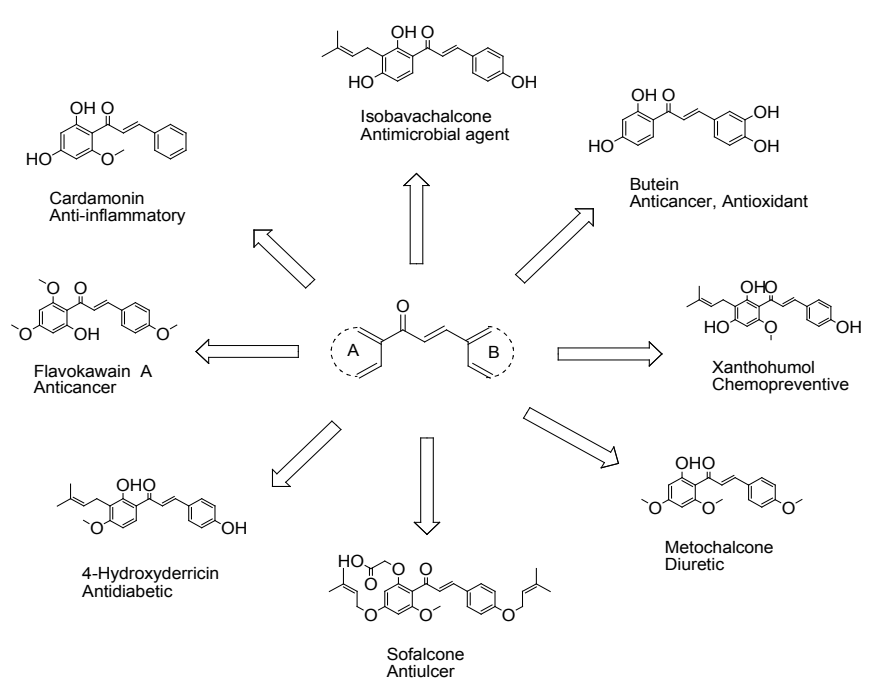

Figure 2: Chalcone scaffold having various pharmacological activities.

et al. synthesized chalcones and their corresponding analogues and found that introduction of pyrazole moiety increases the rigidity of the molecule and show better cytotoxic activity then their corresponding chalcones 4 [22], compound 5 has shown the ability to inhibit P-glycoprotein-mediated multidrug resistance by direct binding to a purified protein domain containing an ATP-binding site and a modulator interacting region [23] whereas compound 6 was assayed for anticancer activity mainly against leukemia (K-562 and SR), renal cancer (UO-31) and non-small cell lung cancer (HOP-92) cell lines, with the most important $\mathrm{GI}_{50}$ values ranging from 0.04 to $11.4 \mu \mathrm{M}$ [24]. Jainey et al. synthesized thiophene based pyrazolines and evaluated for antitumor, analgesic, anti-inflammatory activity compound 7 showed highest toxicity of $80 \%$ at $200 \mu \mathrm{g} / \mathrm{mL}$ and it also showed good analgesic, anti-inflammatory activity so compound bearing electron withdrawing groups on phenyl ring are more active as compared to electron donating [25]. Pyrazoline substituted benzenesulfonylurea compound 8 displayed remarkable antiproliferative activity against leukemia, colon, melanoma, ovarian, renal, prostate and breast cancer cell lines with $\mathrm{GI}_{50}$ less than $2 \mu \mathrm{M}$ [26]. 2- pyrazoline bearing benzene sulfonamide moiety (9) have shown good anti-inflammatory activity as compared to the reference drug celecoxib and compound 10 exhibited promising antiproliferative activity with $\mathrm{GI}_{50}$ values less than $2 \mu \mathrm{M}$ against leukemia cancer, in non-small cell lung cancer, in colon cancer [27] and thiazolyl-pyrazolines compound 11 has shown promising activity against A549 cancer cells with an $\mathrm{IC}_{50}$ value of $62.5 \mu \mathrm{g} / \mathrm{mL}$ [28]. 5-pyrazoline substituted 4-thiazolidinones were synthesized and evaluated against leukemia cell lines, compound 12 showed $\mathrm{GI}_{50}$ value in the range of $2.12-4.58 \mu \mathrm{M}$ and compound 13 in $1.64-3.20 \mu \mathrm{M}$ these also act as good antitrypanosomal and antiviral agents [29]. Pyrazoline derivative 14 was screened for antiproliferative activity against lung (A549), liver (HepG-2), intestinal (CaCo-2) and Breast (MCF-7) cancer cell lines and it has shown promising activity, its activity was due to apoptosis which proceeds via caspase-3 activation [30]. 2 pyrazoline obtained from [(7-chloroquinoline-4-yl)amino] chalcones were synthesized and evaluated for antitumor and antimalarial activity compound 15 showed remarkable antitumor activity with $\mathrm{GI}_{50}$ value ranging from 0.13 to $0.99 \mu \mathrm{M}$ whereas compound 16 has shown best antimalarial response with an inhibition percentage of $50.8 \%$ for Plasmodium falciparum and $\mathrm{IC}_{50}$ of $14.1 \mu \mathrm{g} / \mathrm{mL}$ [31]. Novel series of pyrazoline analogues were synthesized and evaluated for anticancer activity against lung cancer cell line (A549) and compound 17 have shown promising anticancer activity with percent cytotoxicity in the range $36.21-71.24 \mu \mathrm{g} / \mathrm{mL}$ and $\mathrm{GI}_{50}$ in the range of $11.41-43.15 \mu \mathrm{g} / \mathrm{mL}$ [32]. Caffeine based pyrazoline were synthesized and evaluated for antimalarial activity against Plasmodium falciparum the compound 18 showed outstanding growth inhibition percentage $85.2 \pm 5.4$ percent while compound 19 has shown remarkable activity against Leshmania panamensis [33]. Series of pyrazolines were synthesized and evaluated for in vitro anti-tubercular activity against Mycobacterium tuberculosis H37Rv strain. Compound 20 exhibited significant anti-tubercular activity at MIC values $12.5 \mu \mathrm{M}$ concentration [34] . $\alpha$-pyranopyrazoline analogues were synthesized and evaluated for antimalarial activity, compound 21 turned to be the most potent analog of the series having $\mathrm{IC}_{50} 3.1 \mu \mathrm{g} / \mathrm{mL}$ against chloroquine-sensitive strain $3 \mathrm{D} 7$ and $\mathrm{IC}_{50}$ of 1.1 $\mu \mathrm{g} / \mathrm{mL}$ against chloroquine-resistant strain RKL9. To support the data further docking was done into the active site of falciparum enzyme which showed good interaction with the active site residue [35]. 2-pyrazoline and pyrazoles synthesized as celecoxib analogues and evaluated for in vitro COX-1/COX-2 inhibitory activity compound 22 was most selective COX-2 inhibitor [36]. Pyrazoline derivatives originated from pyrano-chalcones have been synthesized and evaluated for their inhibitory potency on the production of inflammatory mediator nitric oxide (NO) in LPS-stimulated RAW 264.7 cells. Compound 23 has shown iNOS activity superior to positive control indomethacin. It also suppress the progress of carrageenan-induced hind paw edema at a dosage of $50 \mathrm{mg} / \mathrm{kg} /$ day and docking studies reveled that it has a good binding into the active site of murine iNOS [37] (Figure 3).

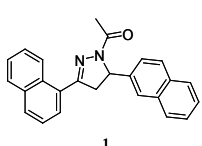<smiles>COc1ccc(CCC(C)C(C)O)cc1</smiles>

4<smiles>Clc1ccc(C2CC(c3cccs3)NN2)cc1</smiles>

7

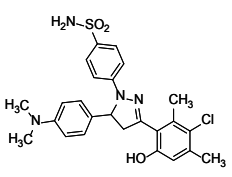

10

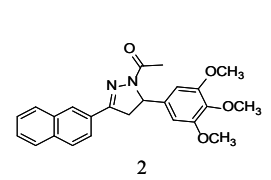<smiles>CC(=O)N1c2ccc(O)cc2CC1c1ccccc1</smiles>

5

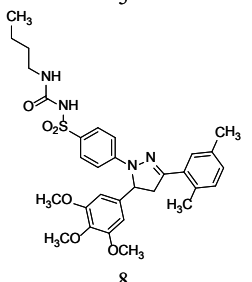

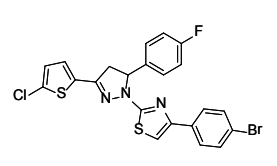

11
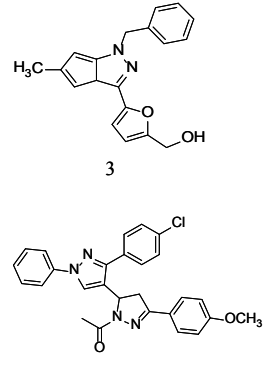

6

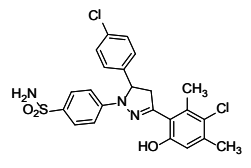

9

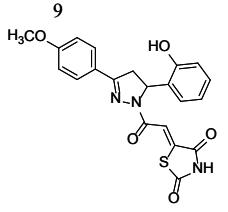




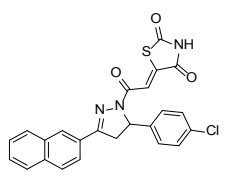

13<smiles>Clc1ccc(C2CC(c3ccc(Br)cc3)NN2c2ccc(-c3ccccc3)nc2)cc1</smiles>

14

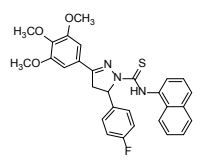

17

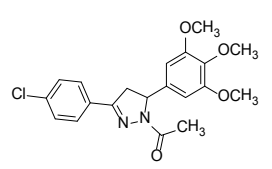

20

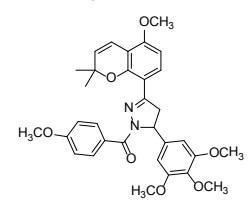

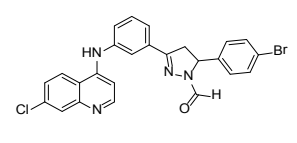

15

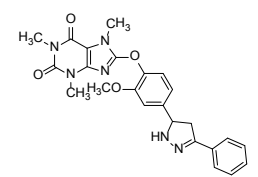

18

21

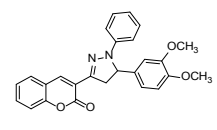<smiles>COc1ccc(CC2(c3ccc(C(F)(F)F)cc3)N=C(c3ccc(N)cc3)c3ccccc32)cc1</smiles>

22
Hamada et al. has synthesized acetoxysulfonamide pyrazole derivatives starting from substituted vanillin chalcones and were tested for antimicrobial activity against Staphylococcus aureus, Candida albicans, and for antioxidant activity, compound 24, 25 which are bearing lipophilic properties and having electron withdrawing groups exhibit great antimicrobial and antioxidant activity [38]. Furan containing pyrzoline compounds (26) having para hydroxyl group in ring A have shown better antioxidant activity than ascorbic acid and reutin [39]. Whereas 2-pyrazoline compounds (27) bearing hydroxyl and methoxy groups in ring A have shown good free radical scavenging activity [40]. Docking study of series of pyrazole derivatives were done using Epidermal Growth Factor Receptor kinase domain (PDB: $1 \mathrm{M} 17$ ) as a target and based on the interaction with the receptor the novel compounds were synthesized and screened for antioxidant and anticancer activity against breast cancer (MCF-7) and lung cancer (A549) cell lines and compounds (28) having electron releasing group on ring $\mathrm{B}$, such as methoxy has shown good antioxidant activity with $\mathrm{IC}_{50} 21 \mu \mathrm{g} / \mathrm{mL}$ whereas compound 29 has shown good interaction with the target as it forms hydrogen bonding with the receptor due to the presence of fluorine at para position on ring $\mathrm{B}$ and it also showed $\mathrm{IC}_{50}$ 3.5 $\mu \mathrm{M}$ against MCF-7 and 17.6 $\mu \mathrm{M}$ against A549 [41] (Figure 4).<smiles>COc1cc(C2CC(c3ccc(Cl)cc3)NN2C(N)=S)ccc1O</smiles><smiles>O=C(c1cccnc1)N(Cc1ccc(Cl)cc1)Cc1ccc(O)c(O)c1</smiles><smiles>COc1cc(C2=NNC(c3ccc(C)cc3)C2)ccc1O</smiles>
27<smiles>COc1ccc(C2=NN(C(N)=S)C(c3ccc(OC)cc3OC)C2)cc1</smiles>

28

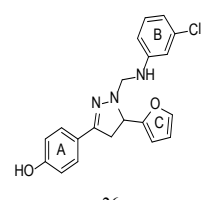

26

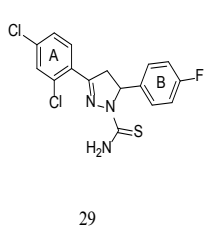

Bano et al. synthesized series of substituted pyrazoline derivatives and were docked on the fluconazole-bound CYP51 from Mycobacterium tuberculosis (MTCYP51) (PDB No: 1EA1) and then these were subjected to antimicrobial activity against Staphylococcus aureus, Escherichia coli, Aspergillus flavus, Avicularia versicolor, Aspergillus fumigatus and Candida albicans compound 30 having a hydroxyl group at meta positon on ring $\mathrm{B}$ has shown good antifungal activity against all the strains having MIC within the range of $12.5-3.125 \mu \mathrm{g} / \mathrm{mL}$ and moderate antibacterial activity. These results were supported by docking studies as drug-receptor interaction showed comparable results with the activity as the pharmacophore having hydroxyl group has maximum free binding energy i.e., $-8.37 \mathrm{kcal} / \mathrm{mol}$ [42]. 2-pyrazoline derivatives bearing benzenesulfonamide moieties were synthesized in order to find the novel antimicrobial agents and tested against Staphylococcus aureus, Escherichia coli, Pseudomonas aeruginosa and Candida albicans compound 31 has shown significant antimicrobial activity against all the strains this shows that molecules having benzene-sulphonamide moiety can act as lead in the discovery of novel antimicrobial agents [43]. A series of chalconolides and its pyrazoline derivatives were synthesized by condensing 1-acetylnapthalenes with 1-napthaldehyde. Then these heterocycles were characterized and then tested for antimicrobial activity against variety of test organisms such as Escherichia coli, Staphylococcus aureus, Klebsiella pneumoniae, Proteus mirabilis, Shigella dysentery and Salmonella typhi. The results showed that the compound 32 having chlorine, hydroxyl and dimethylamino groups as substituents on the naphthalene rings are very effective antimicrobial agents [44]. Pyrrazole of 2-acetyl benzofuran were synthesized and subjected to antimicrobial activity against gram-positive and gram-negative bacteria compound 33 have shown remarkable activity against gram negative bacteria with $25 \mathrm{~mm}$ zone of inhibition and good activity against gram-positive bacteria with $20 \mathrm{~mm}$ zone of inhibition. This

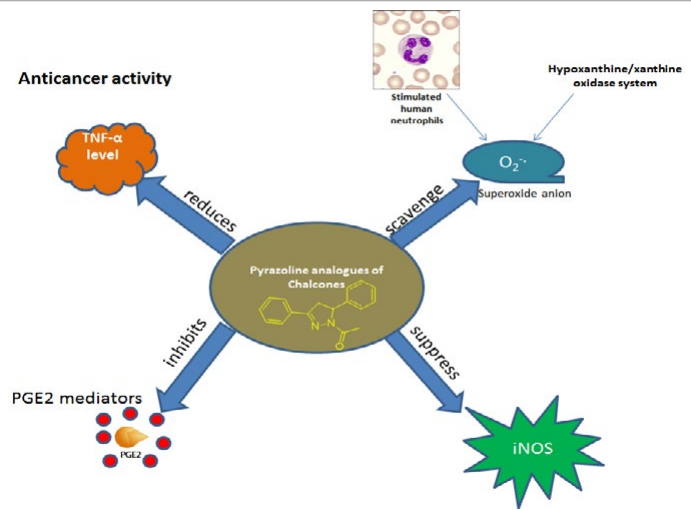

Figure 3: Mechanism of action of pyrazoline analogues of chalcones as anticancer agents.

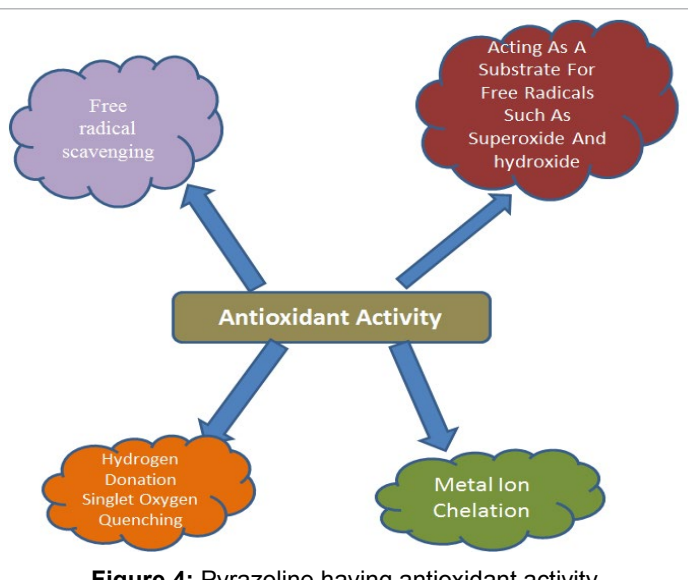

Figure 4: Pyrazoline having antioxidant activity. 
concludes that benzofuran, pyrazoline, and thiazole moieties are vital for the antimicrobial activity [45]. Indole phenyl pyrazoles were synthesized by grind stone method in this aldehyde and ketone were grinded in mortar and pestle in the presence of catalyst which leads to phase change and produces product and these products were tested for antimicrobial activity. Compound 34 has shown promising activity against Staphylococcus aureus, Escherichia coli, Aspergillus niger and Candida albicans with 5-13 mm zone of inhibition [46]. 2-pyrazoline derivatives were designed, synthesized and their antimicrobial activity was performed and compound 35 having chloro and nitro group have shown good antimicrobial activity within the range of 20-70 $\mu \mathrm{g} / \mathrm{mL}$ [47] where as Pyrazoline derivatives having $\mathrm{N}$-acyl arms and homologus alkoxy side chain were screened for in-vitro antiinflammatory activity, compound 36 showed most promising activity having $\mathrm{IC}_{50} 173.06 \pm 2.312 \mathrm{mM}$ which is better than Indomethacin $\left(\mathrm{IC}_{50}\right.$ $273.12 \pm 2.33 \mathrm{mM}$ ). This revealed that compounds with odd number of carbons in alkyloxy side chain are more active than even one [48]. A series of 1-thiocarbamoyl-3-phenyl-5-hydroxy-5-(2-pyridyl)-4-pyrazolines were synthesized and evaluated for antimicrobial activity compound 37 exhibit potent antibacterial and antifungal activity against Salmonella typhi, Pseudomonas aeruginosa, Aspergillus niger and Aspergillus fumigatus having zone of inhibition in the range of 2.5-2 $\mathrm{mm}$ [49]. Novel morpholinoquinoline based pyrazoline was designed and synthesized under microwave irradiation and screened for in vitro antibacterial, antifungal, antimalarial and antitubercular activity. Compound 38 having methoxy group act as antimalarial agent as it act against Plasmodium falciparum and Streptococcus pneumoniae at $15 \mu \mathrm{M}(39)$ have enhanced antifungal activity against Candida albicans with $\mathrm{IC}_{50}$ at $229 \mu \mathrm{M}$ and compound 40 showed $95 \%$ inhibition against Mycobacterium tuberculosis (H37Rv) at $47 \mu \mathrm{M}$ whereas compound 41 is active against Vibrio cholera having MIC at $132 \mu \mathrm{M}$ [50]. Pyrazolines having N -substituted 5-(furan2-yl)-phenyl and 5-(thiophene-2-yl)-phenyl moiety were synthesized and evaluated for antibacterial activity against gram-positive and gramnegative bacteria, compound 42 has shown MIC in the range of 10-30 $\mu \mathrm{g}$ against all the bacteria [51] whereas compound 43 has shown promising antibacterial activity with MIC in the range of 10-40 $\mu \mathrm{g}$ [52]. This concludes that pyrazoline having furan moiety is more active than thiophene moiety containing pyrazolines. Series of Isoniazide-pyrazolines and phenyl pyrazoline were synthesized and tested for antibacterial, antifungal and antitubercular activity compound 44 having isoniazide moiety exhibits significant antibacterial activity against Pseudomonas aeruginosa and Staphylococcus aureus with MIC - $3.12 \mu \mathrm{g} / \mathrm{mL}$ and shows good antifungal activity against Candida albicans with same MIC and it also found to have promising antitubercular activity against Mycobacterium tuberculosis [53]. 2-napthylpyrazoline and Thiazolyl-pyrazolines were evaluated for antibacterial and anticandidal activity compound 45 was active against gram negative bacteria [54] and compound 46 was identified to have good inhibitory effect against Candida zeylanoides with MIC value of $250 \mu \mathrm{g} / \mathrm{mL}$ when compared with ketoconazole [55].
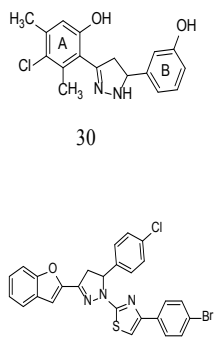

33
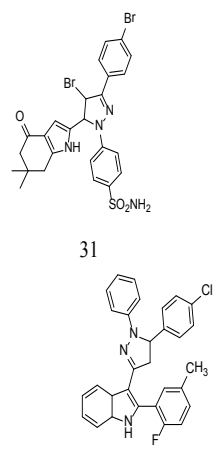

34

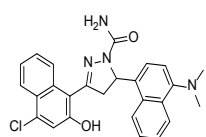

32

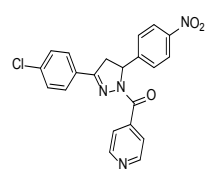

35
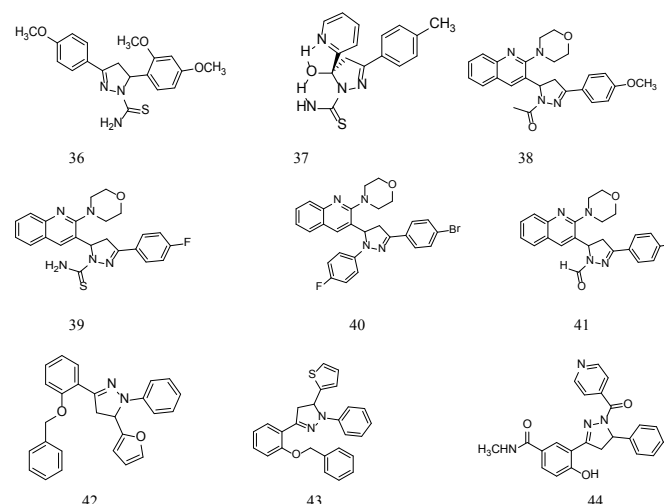

37
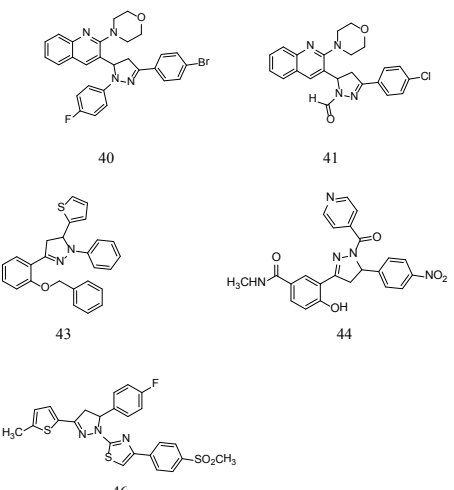

44

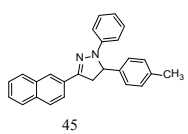

Nepali et al. designed and synthesized series of new pyrazoles and evaluated for in vitro xanthine oxidase inhibitory activity compound 47 was found to be most active with $\mathrm{IC}_{50} 5.3 \mu \mathrm{M}$. the result conclude that the nature and substituents present on the two phenyl rings greatly affect the xanthine oxidase inhibitory activity presence of heteroaryls such as furan, pyridyl and $\mathrm{N}$-acetyl group increases the xanthine oxidase inhibitory activity [55]. Siddiqui et al. synthesized substituted 3,5-diphenyl 2-pyrazoline 1-crboxamide derivatives and tested for anticonvulsant activity compound 48 was protective against maximal electroschok seizer at $100-300 \mathrm{mg} / \mathrm{kg}$ dose levels this shows that these can act as a good lead for anticonvulsant agents [56]. Pyrazoline derivative were designed and tested for MAO inhibitory activity and found that compound 49 having ring $\mathrm{C}$ increases the potency against MAO inhibitory activity [57] whereas compound 50 act as selective $\mathrm{MAO}-\mathrm{B}$ inhibitor and compound 51 having bromine atom appeared to be the most selective MAO-A inhibitor [58]. The results revealed that ring $\mathrm{C}$ is essential for the activity, six-membered ring appears to be selective for MAO-B inhibitory action and five-membered ring showed selectivity to MAO-A (Figure 5).<smiles>CC(=O)N1N=C(c2ccco2)CC1c1ccncc1</smiles>

47

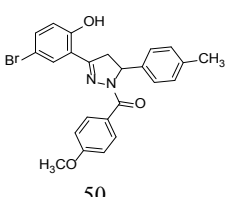

50

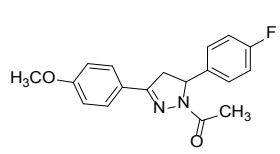

48

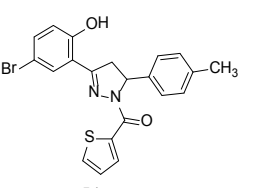

51

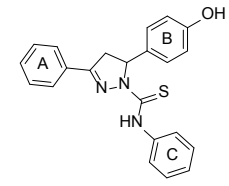

49
Isoxazole analogues: Heterocyclic compounds are known to have various pharmacological activities among them five membered heterocycles mainly isoxazoles have gained the interest of organic and medicinal chemist. Various pharmacological activities of isoxazoles are antiviral [59], anti-inflammatory [60], antimicrobial [61], antihyperglycemic [62] and anticancer [63]. Bano et al. synthesized series of substituted isoxazoline derivatives these were docked on the fluconazole-bound CYP51 from Mycobacterium tuberculosis (MTCYP51) (PDB No:1EA1) and then these were subjected to antimicrobial activity against Staphylococcus aureus, Escherichia coli, Aspergillus flavus, Aspergillus fumigatus and Candida albicans, compound 52 has shown moderate antibacterial activity with 16-22 $\mathrm{mm}$ zone of inhibition and good antifungal activity with MIC 


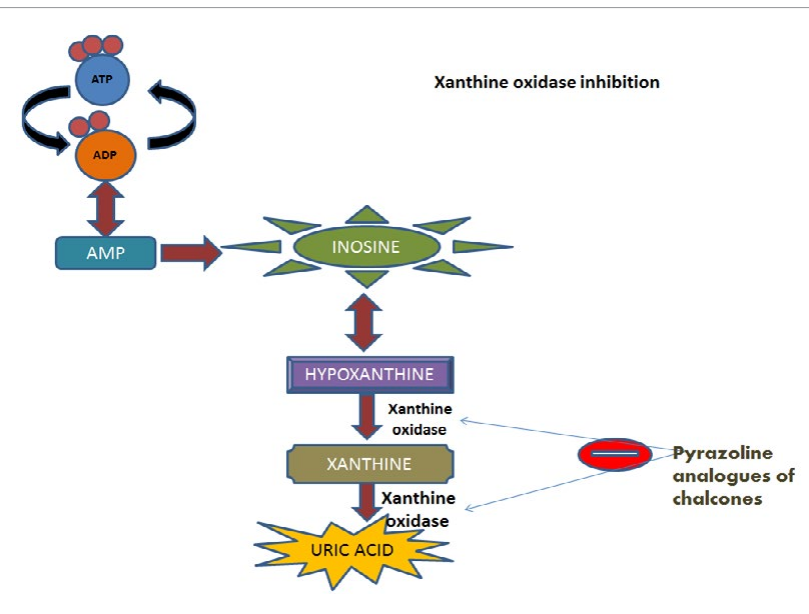

Figure 5: Pyrazoline acting as Xanthin oxidase inhibitor.

ranging from 6.25-12.5 $\mu \mathrm{M}$ [42]. Solankee et al. reported the synthesis of series of substituted isoxazolines and these were screened for antimicrobial activity against gram-positive, gram-negative bacteria and fungal strains, compound 53 has shown good activity against all the strains which states that compound having methoxy, chloro and nitro groups are more potent as compared to others [64]. Benzimidazole isoxazole were synthesized and screened for antimicrobial and anticancer activity and compound 54 has shown 18-25 mm zone of inhibition against antimicrobial strains and isoxazole moiety bearing molecule showed better anticancer activity [65]. Combrestatin analogues having five membered heterocycles (isoxazole, isoxazoline, oxadiazole) were synthesized and evaluated for cytotoxicity and their ability to inhibit the tubulin assembly. The compound 55 showed good antitubulin activity at $1.2 \mu \mathrm{M}$ [66]. Isoxazoline was synthesized and tested for antimicrobial activity against Staphylococcus aureus, Bacillus megaterium, Aspergillus niger and Asterophora parasitica and compound 56 has shown good activity against all strains with $18-22 \mathrm{~mm}$ zone of inhibition [67]. New series of isoxazolidin-3yl-3-phosphonic acids were synthesized and screened for their cytotoxic activity to HeLa and K562 cells compound 57 with $\mathrm{IC}_{50}$ in $0.1-0.3 \mathrm{mM}$ range were found to be most active [68]. Isoxazole derivative of thiophene have shown moderate antimicrobial activity 58 [69]. New series of isoxazolines has been synthesized and has shown moderate antimicrobial activity 59 [70].

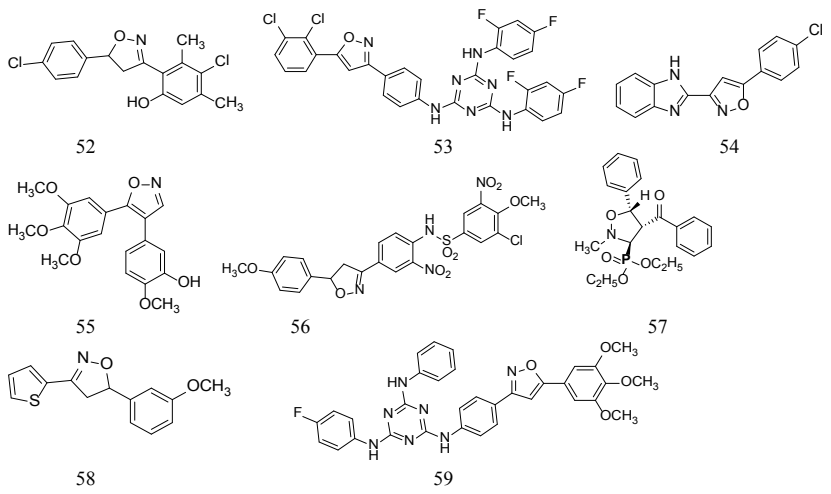

Pyrimidine analogues: $\mathrm{N}$-fused analogues of chalcones particularly pyrimidines have received augmented interest due to their plethora of biological actions such as antifungal [71], antibacterial [72], antitumor [73], analgesics [74], anti-inflammatory [75], anti-trichomonal [76], KDR kinase inhibition [77], CRF-1 receptor antagonists [78,79] estrogen receptor ligands, and COX-2 selective inhibition [80].
Sharma et al. synthesized a series of quinolinyl chalcones and quinolinyl pyrimidines and screened them against $\mathrm{M}$. tuberculosis and NF-54 strains of $P$. falciparum among all compounds with 4-amino linkage showed promising activity against NF-54 strains of $P$. falciparum. Six compounds have shown antitubercular activity with MIC in the range of 3.12-12.5 mg/mL and are nontoxic against VERO and MBMDM cell lines. Four compounds showed antimalarial activity with MIC ranging from 1 to $2 \mathrm{mg} / \mathrm{mL}$. The study reported that quinolinyl chalcones (61) are antitubercular agents while pyrimidine analogues are active against malaria (60) [81].<smiles>[R]c1cc(-c2ccc(Nc3ccnc4cc(Cl)ccc34)cc2)nc(N)n1</smiles>

60<smiles>[R]C=CC(=O)c1ccc(Nc2ccnc3cc(Cl)ccc23)cc1</smiles>

61
In another study a series of pyrimidinyl containing chalcones were synthesized and evaluated for cytotoxicity against several human cancer cell lines. The compounds were screened against KB cells (drug sensitive human oral carcinoma cells) CNE2 cells (drug sensitive human nasopharyngeal carcinoma cells) MGC-803 cells (drug sensitive human gastric carcinoma cells) MCF-7 cells (drug sensitive human breast adenocarcinoma cells) K562 cells (drug sensitive human leukemia cells). The result concluded that compounds containing electron releasing substituents such as methoxyl displayed higher cytotoxicities compared to those with electron withdrawing substituents or no substituents. The compound containing methoxyl group (62) showed more potent cytotoxicity in comparison to curcumin [82].<smiles>[R]c1cc(-c2ccc(Nc3ccnc4cc(Cl)ccc34)cc2)nc(N)n1</smiles>

60<smiles>[R]C=CC(=O)c1ccc(Nc2ccnc3cc(Cl)ccc23)cc1</smiles>

61
Chalcones bearing pyridine motifs are also a good source of anticancer agents, compounds possessing dihydroxylated 2,6-diphenyl4-aryl pyridine derivatives were synthesized via chalcone intermediates and screened for topoisomerase I and II inhibitory activity and cytotoxicity against several cell lines, the position of hydroxyl groups in phenyl rings and types of aryl moieties attached to the central pyridine greatly influenced the pharmacological action [83]. Compounds (63, 64) bearing hydroxyl group at meta or para position of 2- and 6-phenyl rings in combination with 2-furyl, 2-thienyl, or 3-thienyl moiety at 4-position of central pyridine showed significant topo II inhibitory activity and cytotoxicity [84].

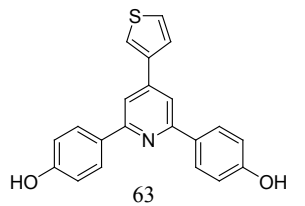

Compound bearing maximum topoisomerase<smiles>Oc1cccc(-c2cc(-c3ccccc3O)cc(-c3cccc(O)c3)n2)c1</smiles>

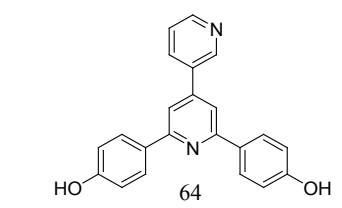

Compounds bearing maximum cytotoxicity activity 
In addition, trihydroxylated derivatives are more potent topoisomerase II inhibitors and cytotoxic agents in comparison to dihydroxylated derivatives and similar author also reported topoisomerase II inhibition and cytotoxic potential of monohydroxylated pyridine derivatives $(64,65)$. Amongst all trihydroxy derivates of pyridine proved to be the most potent agents against topoisomerase II and cytotoxicity $[85,86]$.

\section{Conclusion}

Chalcones not only itself acting as a molecule with diverse pharmacological actions; instead their analogues are too carrying importance for array of medicinal properties. Ring closure of chalcones results in to heterocyclic scaffolds with varied pharmacological properties. The Pyrazoline analogues are reported to possess cytotoxic, antimicrobial, antioxidant and xanthine-oxidase inhibitory action, whereas isoxazoles derived from chalcones are also acting as a key molecule for bundles of biological actions. Moreover six membered heterocycles especially pyridine and pyrimidine analogues are also proved to be the mines of biological actions. Pyridine analogues with certain substitutions such as hydroxyl at different positions proved to be effective against topoisomerase and cytotoxic action.

\section{Acknowledgements}

The authors acknowledge School of Pharmaceutical Sciences, Shoolini University for providing facilities for our work.

\section{References}

1. Bukhari SN, Jantan I, Jasamai M (2013) Anti-inflammatory trends of 1 3-diphenyl-2-propen-1-one derivatives. Mini Rev Med Chem 13: 87-94.

2. Albuquerque MTH, Santos MMC, Cavaleiro ASJ, Silva MSA (2014) Chalcones as Versatile Synthons for the Synthesis of 5-and 6-membered Nitrogen Heterocycles. Current Organic Chemistry 18: 2750-2775.

3. Mathew B, Suresh J, Anbazghagan S, Paulraj J, Krishnan GK (2014) Heteroaryl chalcones: Mini review about their therapeutic voyage. Biomedicine \& Preventive Nutrition 4: 451-458.

4. Fang X, Yang B, Cheng Z, Zhang P, Yang M (2014) Synthesis and antimicrobial activity of novel chalcone derivatives. Research on Chemical Intermediates 40: 1715-1725.

5. Tran TD, Nguyen TT, Do TH, Huynh TN, Tran CD, et al. (2012) Synthesis and antibacterial activity of some heterocyclic chalcone analogues alone and in combination with antibiotics. Molecules 17: 6684-6696.

6. Zhang XW, Zhao DH, Quan YC, Sun LP, Yin XM, et al. (2010) Synthesis and evaluation of antiinflammatory activity of substituted chalcone derivatives. Medicinal chemistry research 19: 403-412.

7. Bandgar BP, Gawande SS, Bodade RG, Totre JV, Khobragade CN (2010) Synthesis and biological evaluation of simple methoxylated chalcones as anticancer, anti-inflammatory and antioxidant agents. Bioorg Med Chem 18: 1364-1370.

8. Samshuddin S, Narayana B, Sarojini BK, Khan MTH, Yathirajan HS, et al. (2012) Antimicrobial, analgesic, DPPH scavenging activities and molecular docking study of some 1, 3, 5-triaryl-2-pyrazolines. Medicinal Chemistry Research 21: 2012-2022.

9. Yadav N, Dixit SK, Bhattacharya A, Mishra LC, Sharma M, et al. (2012) Antimalarial activity of newly synthesized chalcone derivatives in vitro. Chemical biology \& drug design 80: 340-347.

10. Doan TN, Tran DT (2011) Synthesis, antioxidant and antimicrobial activities of a novel series of chalcones, pyrazolic chalcones, and allylic chalcones. Pharmacology \& Pharmacy 2: 282-288.

11. Zhang H, Liu JJ, Sun J, Yang XH, Zhao TT, et al. (2012) Design, synthesis and biological evaluation of novel chalcone derivatives as antitubulin agents. Bioorganic \& medicinal chemistry 20: 3212-3218

12. Hans RH, Guantai EM, Lategan C, Smith PJ, Wan B, et al. (2010) Synthesis, antimalarial and antitubercular activity of acetylenic chalcones. Bioorganic \& medicinal chemistry letters 20: 942-944.
13. Hayat F, Moseley E, Salahuddin A, Van Zyl RL, Azam A (2011) Antiprotozoal activity of chloroquinoline based chalcones. Eur J Med Chem 46: 1897-1905.

14. Aponte JC, Castillo D, Estevez Y, Gonzalez G, Arevalo J, et al. (2010) In vitro and in vivo anti-Leishmania activity of polysubstituted synthetic chalcones. Bioorganic \& medicinal chemistry letters 20: 100-103.

15. Beyhan N, Kocyigit-Kaymakcioglu B, Gümrü S, Aricioglu F (2013) Synthesis and anticonvulsant activity of some 2-pyrazolines derived from chalcones. Arabian Journal of Chemistry.

16. Syam S, Abdelwahab SI, Al-Mamary MA, Mohan S (2012) Synthesis of chalcones with anticancer activities. Molecules 17: 6179-6195.

17. Wu MH, Yang XH, Zou WD, Liu WJ, Li C (2006) Refinement of the crysta structure of $(E)-1, \quad 3-d i p h e n y l-2-p r o p e n-1-o n e, C_{15} \mathrm{H}_{12} \mathrm{O}$. Zeitschrift für Kristallographie-New Crystal Structures 221: 323-324.

18. Zenger K, Dutta S, Wolff H, Genton MG, Kraus B (2015) In vitro structuretoxicity relationship of chalcones in human hepatic stellate cells. Toxicology 336: 26-33.

19. Nepali K, Kadian K, Ojha R, Dhiman R, Garg A, et al. (2012) Effect of ring A and ring $B$ substitution on the cytotoxic potential of pyrazole tethered chalcones. Medicinal Chemistry Research 21: 2990-2997.

20. Ethiraj K, Nithya P, Krishnakumar V, Mathew AJ, Khan FN (2013) Synthesis and cytotoxicity study of pyrazoline derivatives of methoxy substituted naphthy chalcones. Research on Chemical Intermediates 39: 1833-1841.

21. Chou LC, Huang LJ, Yang JS, Lee FY, Teng CM (2007) Synthesis of furopyrazole analogs of 1-benzyl-3-(5-hydroxymethyl-2-furyl) indazole (YC-1) as novel antileukemia agents. Bioorganic \& medicinal chemistry 15: 1732-1740.

22. Bhat B, Dhar K, Puri S, Saxena A, Shanmugavel M, et al. (2005) Synthesis and biological evaluation of chalcones and their derived pyrazoles as potential cytotoxic agents. Bioorganic \& medicinal chemistry letters 15: 3177-3180.

23. Manna F, Chimenti F, Fioravanti R, Bolasco A, Secci D, et al. (2005) Synthesis of some pyrazole derivatives and preliminary investigation of their affinity binding to P-glycoprotein. Bioorganic \& medicinal chemistry letters 15: 4632-4635.

24. Insuasty B, Tigreros A, Orozco F, Quiroga J, Abonía R, et al. (2010) Synthesis of novel pyrazolic analogues of chalcones and their 3-aryl-4-(3-aryl-4, 5-dihydro1H-pyrazol-5-yl)-1-phenyl-1 H-pyrazole derivatives as potential antitumor agents. Bioorganic \& medicinal chemistry 18: 4965-4974.

25. Jainey P, Bhat I (2012) Antitumor, Analgesic, and Anti-inflammatory Activities of Synthesized Pyrazolines. J Young Pharm 4: 82-87.

26. Rathore P, Yaseen S, Ovais S, Bashir R, Yaseen R, et al. (2014) Synthesis and evaluation of some new pyrazoline substituted benzenesulfonylureas as potential antiproliferative agents. Bioorganic \& medicinal chemistry letters 24 : 1685-1691.

27. Bano S, Javed K, Ahmad S, Rathish I, Singh S, et al. (2011) Synthesis and biological evaluation of some new 2-pyrazolines bearing benzene sulfonamide moiety as potential anti-inflammatory and anti-cancer agents. European journal of medicinal chemistry 46 : 5763-5768.

28. Altintop MD, Özdemir A, Turan-Zitouni G, Ilgin S, Atli Ö, et al. (2015) A nove series of thiazolyl-pyrazoline derivatives: synthesis and evaluation of antifungal activity, cytotoxicity and genotoxicity. European journal of medicinal chemistry 92: 342-352.

29. Havrylyuk D, Zimenkovsky B, Vasylenko O, Day CW, Smee DF, et al. (2013) Synthesis and biological activity evaluation of 5-pyrazoline substituted 4-thiazolidinones. European journal of medicinal chemistry 66: 228-237.

30. George RF, Fouad MA, Gomaa IE (2016) Synthesis and cytotoxic activities of some pyrazoline derivatives bearing phenyl pyridazine core as new apoptosis inducers. European Journal of Medicinal Chemistry 112: 48-59.

31. Insuasty B, Montoya A, Becerra D, Quiroga J, Abonia R, et al. (2013) Synthesis of novel analogs of 2-pyrazoline obtained from [(7-chloroquinolin-4-yl) amino] chalcones and hydrazine as potential antitumor and antimalarial agents. European journal of medicinal chemistry 67: 252-262.

32. Lu ZH, Gu XJ, Shi KZ, Li X, Chen DD, et al. (2014) Accessing anti-human lung tumor cell line (A549) potential of newer 3,5-disubstituted pyrazoline analogs. Arabian Journal of Chemistry.

33. Insuasty B, Ramírez J, Becerra D, Echeverry C, Quiroga J, et al. (2015) An efficient synthesis of new caffeine-based chalcones, pyrazolines and pyrazolo $[3,4-b][1,4]$ diazepines as potential antimalarial, antitrypanosomal and antileishmanial agents. European journal of medicinal chemistry 93: 401-413. 
34. Pathak V, Maurya HK, Sharma S, Srivastava KK, Gupta A (2014) Synthesis and biological evaluation of substituted 4, 6-diarylpyrimidines and 3, 5-diphenyl-4, 5-dihydro-1 $\mathrm{H}$-pyrazoles as anti-tubercular agents. Bioorganic \& medicinal chemistry letters 24: 2892-2896.

35. Wanare G, Aher R, Kawathekar N, Ranjan R, Kaushik NK, et al. (2010) Synthesis of novel a-pyranochalcones and pyrazoline derivatives as Plasmodium falciparum growth inhibitors. Bioorganic \& medicinal chemistry letters 20: 4675-4678.

36. Abdellatif KR, Elshemy HA, Azoz AA (2015) 1-(4-Methane (amino) sulfonylphenyl)-3-(4-substituted-phenyl)-5-(4-trifluoromethylphenyl)-1 H-2pyrazolines/pyrazoles as potential anti-inflammatory agents. Bioorganic chemistry 63: 13-23.

37. He J, Ma L, Wei Z, Zhu J, Peng F, et al. (2015) Synthesis and biological evaluation of novel pyrazoline derivatives as potent anti-inflammatory agents. Bioorganic \& medicinal chemistry letters 25: 2429-2433.

38. Hamada NMM, Abdo NYM (2015) Synthesis, Characterization, Antimicrobia Screening and Free-Radical Scavenging Activity of Some Novel Substituted Pyrazoles. Molecules 20: 10468-10486.

39. Jagadish $P$, Soni N, Verma A (2013) Design, synthesis, and in vitro antioxidan activity of 1, 3,5-trisubstituted-2-pyrazolines derivatives. Journal of Chemistry.

40. Kumar A, Varadaraj BG, Singla RK (2013) Synthesis and evaluation of antioxidant activity of novel 3, 5-disubstituted-2-pyrazolines. Bulletin of Faculty of Pharmacy, Cairo University 51: 167-173.

41. Mubeen M, Kini SG, Pai K (2015) Design, synthesis, antioxidant and anticancer activity of novel pyrazole derivatives. Der Pharma Chemica 7: 215-223.

42. Bano S, Alam MS, Javed K, Dudeja M, Das AK, et al. (2015) Synthesis, biological evaluation and molecular docking of some substituted pyrazolines and isoxazolines as potential antimicrobial agents. European journal of medicinal chemistry 95: 96-103.

43. Hassan SY (2013) Synthesis, antibacterial and antifungal activity of some new pyrazoline and pyrazole derivatives. Molecules 18: 2683-2711.

44. Azarifar D, Shaebanzadeh M (2002) Synthesis and characterization of new 3 5-dinaphthyl substituted 2-pyrazolines and study of their antimicrobial activity. Molecules 7: 885-895.

45. Abdel-Wahab BF, Abdel-Aziz HA, Ahmed EM (2009) Synthesis and antimicrobial evaluation of 1-(benzofuran-2-yl)-4-nitro-3-arylbutan-1-ones and 3-(benzofuran-2-yl)-4, 5-dihydro-5-aryl-1-[4-(aryl)-1, 3-thiazol-2-yl]-1Hpyrazoles. European journal of medicinal chemistry 44: 2632-2635.

46. Pathak VN, Gupta R, Gupta N (2008) Synthesis and biological evaluation of some new 4, 5-dihydro-3-(2-aryl-indo1-3-yl)-5-(4-chlorophenyl)-N 1)-phenylpyrazoles. Indian journal of chemistry. Section $B$, Organic including medicinal 47: 1303-1307.

47. Dipankar B, Panneerselvam P, Asish B (2012) Synthesis, characterization and antimicrobial activities of some 2-pyrazoline derivatives. Asian J Pharm Clin Res 5: 42-46.

48. Abbas A, Naseer MM (2014) Synthesis and anti-inflammatory activity of new $\mathrm{N}$-acyl-2-pyrazolines bearing homologous alkyloxy side chains. Acta Chim Slov 61: $792-802$

49. Chinnaraja D, Rajalakshmi R, Latha V, Manikandan H (2013) Synthesis spectral characterization and biological evaluation of 1-thiocarbamoyl-3phenyl-5-hydroxy-5-(-2-pyridyl)-4-pyrazolines via Michael addition. Journal of Saudi Chemical Society.

50. Karad SC, Purohit VB, Thakor P, Thakkar VR, Raval DK (2016) Nove morpholinoquinoline nucleus clubbed with pyrazoline scaffolds: Synthesis, antibacterial, antitubercular and antimalarial activities. European Journal of Medicinal Chemistry 112: 270-279.

51. Rani M, Yusuf M, Khan SA, Sahota P, Pandove G (2015) Synthesis, studies and in-vitro antibacterial activity of $\mathrm{N}$-substituted 5-(furan-2-yl)-phenyl pyrazolines. Arabian Journal of Chemistry 8: 174-180.

52. Rani M, Mohamad $Y$ (2014) Synthesis, studies and in vitro antibacterial activity of some 5-(thiophene-2-yl)-phenyl pyrazoline derivatives. Journal of Saudi Chemical Society 18: 411-417.

53. Ahmad A, Husain A, Khan SA, Mujeeb M, Bhandari A (2014) Synthesis, antimicrobial and antitubercular activities of some novel pyrazoline derivatives. Journal of Saudi Chemical Society.
54. Sakthinathan SP, Anangamudi G, Thirunarayanan G (2012) Synthesis, spectra studies and antimicrobial activities of some 2-naphthyl pyrazoline derivatives. Spectrochimica Acta Part A: Molecular and Biomolecular Spectroscopy 95: 693-700.

55. Nepali K, Singh G, Turan A, Agarwal A, Sapra S, et al. (2011) A rational approach for the design and synthesis of 1-acetyl-3, 5-diaryl-4, 5-dihydro $(1 \mathrm{H})$ pyrazoles as a new class of potential non-purine xanthine oxidase inhibitors. Bioorganic \& medicinal chemistry 19: 1950-1958.

56. Siddiqui AA, Rahman MA, Shaharyar M, Mishra R (2010) Synthesis and anticonvulsant activity of some substituted 3, 5-diphenyl-2-pyrazoline-1carboxamide derivatives. Chemical Sciences Journal.

57. Jagrat M, Behera J, Yabanoglu S, Ercan A, Ucar G (2011) Pyrazoline based MAO inhibitors: synthesis, biological evaluation and SAR studies. Bioorganic \& medicinal chemistry letters 21: 4296-4300.

58. Evranos-Aksöz B, Yabanoglu-Çiftçi S, Uçar G, Yelekçi K, Ertan R (2014) Synthesis of some novel hydrazone and 2-pyrazoline derivatives: Monoamine oxidase inhibitory activities and docking studies. Bioorganic \& medicinal chemistry letters, $24: 3278-3284$.

59. Makarov VA, Riabova OB, Granik VG, Wutzler P, Schmidtke M (2005) Nove [(biphenyloxy) propyl] isoxazole derivatives for inhibition of human rhinovirus 2 and coxsackievirus B3 replication. Journal of Antimicrobial Chemotherapy 55: $483-488$

60. Habeeb AG, Praveen Rao P, Knaus EE (2001) Design and synthesis of 4 5-diphenyl-4-isoxazolines: novel inhibitors of cyclooxygenase-2 with analgesic and antiinflammatory activity. Journal of Medicinal chemistry 44: 2921-2927.

61. Padmaja A, Payani T, Reddy GD, Padmavathi V (2009) Synthesis, antimicrobial and antioxidant activities of substituted pyrazoles, isoxazoles, pyrimidine and thioxopyrimidine derivatives. European Journal of Medicinal Chemistry 44 4557-4566.

62. Kumar A, Maurya RA, Sharma S, Ahmad P, Singh A, et al. (2009) Design and synthesis of 3,5-diarylisoxazole derivatives as novel class of anti-hyperglycemic and lipid lowering agents. Bioorganic \& medicinal chemistry 17: 5285-5292.

63. Diana P, Carbone A, Barraja P, Kelter G, Fiebig HH, et al. (2010) Synthesis and antitumor activity of 2, 5-bis (3'-indolyl)-furans and 3, 5-bis (3'-indolyl)isoxazoles, nortopsentin analogues. Bioorganic \& medicinal chemistry 18 4524-4529.

64. Solankee A, Patel K, Patel R (2013) Antimicrobial evaluation of some nove isoxazoles, cyanopyridines and pyrimidinthiones. Indian J Chem Sect B 52 671-676.

65. Vekariya N, Khunt M, Parikh A (2003) Synthesis of isoxazoles and quinoxalines as potential anticancer agents. Indian Journal of Chemistry Section B 42: 421 424

66. Kaffy J, Pontikis R, Carrez D, Croisy A, Monneret C, et al. (2006) Isoxazole-type derivatives related to combretastatin $A-4$, synthesis and biological evaluation. Bioorg Med Chem 14: 4067-4077.

67. Gantla CR, Suresh Y, Harikrishana S, Shrivastava S (2009) Synthesis and antibacterial activity of some substituted isoxazolines and isothiazolines. Oriental Journal of Chemistry 25: 153-157.

68. Piotrowska DG, Cieslak M, Krolewska K, Wroblewski AE (2011) Design synthesis and cytotoxicity of a new series of isoxazolidines derived from substituted chalcones. Eur J Med Chem 46: 1382-1389.

69. Gautam KC, Singh DP (2013) Synthesis and Antimicrobial Activity of Some Isoxazole Derivatives of Thiophene. Chemical Science Transactions 2: 992-996.

70. Solankee A, Thakor I (2006) Synthesis of pyrazolines, isoxazolines and aminopyrimidines as biological potent agents. Indian Journal of Chemistry 45 517-522.

71. Novinson T, Robins RK, Matthews TR (1977) Synthesis and antifungal properties of certain 7-alkylaminopyrazolo[1,5-a]pyrimidines. J Med Chem 20: 296-299.

72. El-Gaby MSA, Atalla AA, Gaber A, Al-Wahab KA (2000) Studies on aminopyrazoles: antibacterial activity of some novel pyrazolo [1,5-a] pyrimidines containing sulfonamido moieties. II Farmaco 55: 596-602.

73. Ding R, He Y, Xu J, Liu H, Wang X, et al. (2010) Synthesis and biological evaluation of pyrazolo[1,5-a]-pyrimidine-containing 99mTc Nitrido radiopharmaceuticals as imaging agents for tumors. Molecules 15: 8723-8733. 
Citation: Sapra S, Sharma K, Bhalla Y, Dhar KL (2016) Chalconoid Derived Heterocycles as Potent Bioactive Molecules: A Review. Chem Sci J 7: 129. doi:10.4172/2150-3494.1000129

74. Shaaban MR, Saleh TS, Mayhoub AS, Mansour A, Farag AM (2008) Synthesis and analgesic/anti-inflammatory evaluation of fused heterocyclic ring systems incorporating phenylsulfonyl moiety. Bioorganic \& medicinal chemistry 16: 6344-6352.

75. Auzzi G, Bruni F, Cecchi L, Costanzo A, Vettori PL, et al. (1983) 2-Phenylpyrazolo [1, 5-a] pyrimidin-7-ones. A new class of nonsteroidal antiinflammatory drugs devoid of ulcerogenic activity. Journal of medicinal chemistry 26: 1706-1709.

76. Senga K, Novinson T, Springer RH, Rao RP, O'Brien DE, et al. (1975) Synthesis and antitrichomonal activity of certain pyrazolo [1, 5-a] pyrimidines. Journal of medicinal chemistry 18: 312-314.

77. Fraley ME, Hoffman WF, Rubino RS, Hungate RW, Tebben AJ, et al. (2002) Synthesis and initial SAR studies of 3, 6-disubstituted pyrazolo [1,5a] pyrimidines: a new class of KDR kinase inhibitors. Bioorganic \& Medicinal Chemistry Letters 12: 2767-2770.

78. Wustrow DJ, Capiris T, Rubin R, Knobelsdorf JA, Akunne H, et al. (1998) Pyrazolo[1,5-a]pyrimidine CRF-1 receptor antagonists. Bioorg Med Chem Lett 8: 2067-2070.

79. Gilligan PJ, Baldauf C, Cocuzza A, Chidester D, Zaczek R, et al. (2000) The discovery of 4-(3-pentylamino)-2, 7-dimethyl-8-(2-methyl-4-methoxyphenyl)pyrazolo-[1, 5-a]-pyrimidine: A corticotropin-releasing factor (hCRF 1) antagonist. Bioorganic \& medicinal chemistry 8: 181-189.
80. Compton DR, Sheng S, Carlson KE, Rebacz NA, Lee IY, et al. (2004) Pyrazolo $[1,5-a]$ pyrimidines: estrogen receptor ligands possessing estrogen receptor $B$ antagonist activity. Journal of medicinal chemistry 47: 5872-5893.

81. Sharma M, Chaturvedi V, Manju Y, Bhatnagar S, Srivastava K, et al. (2009) Substituted quinolinyl chalcones and quinolinyl pyrimidines as a new class of anti-infective agents. European journal of medicinal chemistry 44: 2081-2091.

82. Jin C, Liang YJ, He H, Fu L (2013) Synthesis and antitumor activity of novel chalcone derivatives. Biomed Pharmacother 67: 215-217.

83. Karki R, Thapa P, Kang MJ, Jeong TC, Nam JM, et al. (2010) Synthesis topoisomerase I and II inhibitory activity, cytotoxicity, and structure-activity relationship study of hydroxylated 2, 4-diphenyl-6-aryl pyridines. Bioorganic \& medicinal chemistry 18: 3066-3077.

84. Karki R, Thapa P, Yoo HY, Kadayat TM, Park PH, et al. (2012) Dihydroxylated 2, 4, 6-triphenyl pyridines: Synthesis, topoisomerase I and II inhibitory activity, cytotoxicity, and structure-activity relationship study. European journal of medicinal chemistry 49: 219-228.

85. Karki R, Park C, Jun KY, Jee JG, Lee JH, et al. (2014) Synthesis, antitumor activity, and structure-activity relationship study of trihydroxylated 2, 4 6-triphenyl pyridines as potent and selective topoisomerase II inhibitors. European journal of medicinal chemistry 84: 555-565.

86. Karki R, Song C, Kadayat TM, Magar TBT, Bist G, et al. (2015) Topoisomerase I and II inhibitory activity, cytotoxicity, and structure-activity relationship study of dihydroxylated 2, 6-diphenyl-4-aryl pyridines. Bioorganic \& medicinal chemistry 23: 3638-3654. 